\title{
A LINHAGEM DA CRIAÇÃO NO ENSINO DE DESIGN NO BRASIL PELOS ESCRITOS DO P\&D 2014 E 2012
}

Cecilia Oliveira Boanova

Instituto Federal Sul-rio-grandense - IFSul

Universidade Federal de Pelotas - UFPel

ceciliaboanova@gmail.com

Resumo: Essa escritura se dedica a apresentar a revisão de literatura sobre a temática da criação no ensino de Design no Brasil, para compor essa tarefa foram recolhidos movimentos registrados de um corpus de (19) artigos publicados em duas ocorrências do evento P\&D dos anos de 2014 e 2012. Os movimentos descobertos deram origem a um mapa daquilo que tem perpassado o processo de criação em Design nas academias do Brasil contemporâneo. Esse mapa é parte integrante do objeto bruto que foi construído para a pesquisa de doutoramento que tem como temática central a educação como foco no ensino de Design enquanto algo é criado. Dentre as implicações foram mapeados cinco movimentos que dizem primeiro de uma proximidade das criações com a cultura brasileira e com aspectos da limitação humana que marcam o afastamento da reprodução de tendências internacionais e da visão do Design como atividade de elite; passando para as criações que fizeram agenciamentos com arte e produziram modos alternativos de conectar elementos para realizar o diálogo entre Arte e Design; seguindo para o entendimento da necessidade de elaborar, usar e criar os frameworks, mostrando o quanto boa parte da forma de expressão do Design é semiaberta e previamente estabelecida; adiante estão as criações ou os pensamentos que escoam da grade, naqueles que tem variado e resistido as pré amarrações existentes no plano de expressão e, por último, os movimentos que ficam da borderline da criação indicando aspectos de algo anterior ou posterior ao produto criado, mas não diretamente ao seu processo. Assim a revisão de literatura contribui, em parte, para a compreensão das formas de criar das academias brasileiras o que colabora para que a partir delas se possa descobrir quais outros modos de criar estudantes e professores tem realizado.

Palavras-chave: Educação; Ensino; Design; Criação

Abstract: This article is dedicated to present the literature review on the topic of creation in the teaching of Design in Brazil, to compose this task were collected the recorded movements in a corpus of (19) articles published in two occurrences of the event $P$ \& D during the years 2014 and 2012. The discovered movements gave origin to a map that has permeated 
the process of creation in Design in the academies of contemporary Brazil. This map is part of the gross object that was built for the PhD research that has as its central theme education focused on teaching Design while something is created. Among the implications were mapped five movements that first say about the proximity of the creations with Brazilian culture and aspects of human limitation that marks the disconnection with international trends and the vision of Design as an elite activity; then talk about the creations that made assemblage with art and produced alternative ways of connecting elements to make the dialogue between Art and Design; followed subsequently by the understanding of the need to develop, use and create frameworks showing how much of the form of expression in Design is semi-opened and previously established; ahead there are the creations or the thoughts that flow from the grid, those who have varied and resisted the preexisting moorings in the expression plane and, finally, the movements that are at the creation borderline indicating aspects of something which happened before or after to the created product, but not directly related to its process. Thus the literature review contributes in part to the understanding of ways to create the Brazilian academies which contributes to discover from them other ways of creating students and teachers have used.

Keywords: Education; Teaching; Design; Creation

\section{INTRODUÇÃO}

Durante o processo de trabalho de um professor, o ritual mágico da devora intelectual nunca termina, agora no tempo da alvorada, depois de passar noites ingerindo textos, alimentando-se, tendo alucinações, delírios e até indigestão, o pensamento e o corpo professoral encontraram um outro estado, foram modificados e fortalecidos. A vontade de ganhar mais força faz da devora de outros um eterno retorno, assim cada novo texto que fala sobre aquilo que o Design inventa, coloca um ponto no mapa da criação que aqui se apresenta. Desta forma, o mapa da criação no Design é resultado do desejo de incorporar as forças da linhagem que o produziu, habitar seus territórios, delirar junto, algo que só foi possível pela devora da musculatura textual reunida de um corpus de (19) artigos publicados em duas ocorrências do evento P\&D dos anos de 2014 e 2012. Os textos foram elaborados por pesquisadores brasileiros que se dedicaram a abordar aspectos da criação no Design em meio ao ensino. O critério de escolha se deu pela presença da palavra "criação" existente nos títulos dos textos. A apreciação e análise cuidou de mapear qualitativamente os movimentos que circularam o tema da criação, o que acabou por oferecer uma categorização de cinco itens que se seguem no decorrer.

Essa escritura trata-se então de um recorte de pesquisa de doutorado, de abordagem qualitativa com pistas cartográficas, no qual se desenvolveu a revisão de literatura contingenciada pelo desejo de descobrir o que anda perpassando o processo de criação em Design nas academias do Brasil atual? Como vem se estabelecendo esse movimento que teima em reencarnar a vida no Design? Esses litígios permitem ver, movimentar e percorrer, pelo rigor e ou pelo delírio, a possibilidade de gerar o 
embrião que dará vida ao rebento "texto de doutoramento" que tem como temática central a educação que contempla o ensino e a criação no Design.

\section{DESENVOLVIMENTO}

O processo de elaboração, que manteve vivo o interesse central, procurou mapear as multiplicidades que perpassam o complexo e ativo processo de criação, tornando necessário aqui salientar as dificuldades envolvidas em qualquer diagnóstico dessa natureza, tanto pelas superposições de conteúdos que inevitavelmente ocorrem e que em outros momentos mostram-se inacomodáveis. Nesse sentido, sempre existem bifurcações e lentes que levam a uma escolha dentre outras possíveis. A lente aqui foi forjada nas filosofias da diferença que propõem um pensar com os conceitos e não somente a partir deles, especialmente pelos escritos de Gilles Deleuze e Félix Guattari. $O$ desafio é dedicar-se as singularidades e as particularidades que habitam cada circunstância, sem sobreposição a olhares paralelos e distintos que podem perfeitamente serem complementares (DELEUZE; GUATARRI, 1995; 1977; 1992; 1997a).

Assim explicita-se as temáticas reunidas e a quantidade de artigos conforme exposto acima: Criação de coisas/produtos que superam críticas (3); Pensar com Arte (3); Grade de referência (frameworks) - o semiaberto da forma de expressão (2); Entrelaçamentos e contaminações no processo criativo - escoamentos da grade (2); Na borderline da criação (9).

\subsection{Criação de coisas/produtos que superam críticas}

A devora textual faz ver a criação de coisas que impunham uma certa atitude ética, estética e política contrária às críticas, produzidas em outros tempos, que denunciavam a dificuldade herdada pelo Design em estabelecer um maior diálogo social, muito por conta da insistência no acompanhamento e reprodução de tendências internacionais, em detrimento da valorização do contexto local, resultando a ele, ser visto como uma atividade de elite (BAHIA et al., 2012). O sabor tênue chega daqueles com capacidade para superar as críticas já que criaram, no Design de Moda, coisas a partir da cultura (pau-Brasil) e de aspectos da limitação humana, a partir de uma escolha que olha para grupos que tomam chimarrão, dançam maracatu e possuem baixa visão ou cegueira. Os objetos criados mantem estreito diálogo social sendo eles: bolsas sustentáveis (ecobags) com estampas da cultura gaúcha (BALESTRIN, 2014), estamparias de tecidos criadas a partir dos elementos do maracatu pernambucano (LIMA et al., 2012) e linha de camisetas com estampas táteis para deficientes visuais (PACHECO et al., 2014). A partir dessas experiências é possível dizer que o ensino vem criando variação, seja por necessidade expressiva/educativa ou pelo simples aprimoramento do olhar que considera os hábitos e os signos da cultura brasileira ou simplesmente pensando nas limitação humanas como no caso das estampas para cegos. $O$ sabor ofertados por esses autores tem potência de oxigenação marcando uma área forte no território da criação, que muito se afasta da reprodução e de movimentos servientes de tendências internacionais, dessa forma eles borram com força e propriedade - uma verdade já naturalizada - o Design como uma atividade para as elites. 


\subsection{Pensar com arte}

Mais um sabor se apresenta aos sentidos, logo nas primeiras páginas percebese algo potente que faz aquecer a nuca e clarear a visão. Agora aparecem as criações que privilegiaram um pensar com arte já que se ocuparam de agenciar com elementos como: um poema que na criação, do Design de Superfície, dá a vida a uma cerâmica (ROSSO et al., 2012), enquanto os vetores da Vanguarda Futurista Italiana e a Arquitetura urbana atual habitam peças de vestuário com estampas anatômicas para o Design de Moda (MAROSO; MINUZZI, 2012) e o Design da Informação e a composição visual apoiam a construção da atmosfera fílmica de um documentário animado (MARTINS, 2012). Como num rasgo que congela o tempo, é dispensável falar de suas minucias. O destaque aqui, fortalece outra parte importante do mapa da criação, aquela que sinalização modos alternativos de explorar entrecruzamentos hibridizações de momentos históricos distantes que alcançaram o diálogo entre arte e Design. Os projetos tem forte relevância como documentos acadêmicos, pois experimentaram uma outra possibilidade de criação evidenciando soluções formais e estéticas em perspectivas singulares. Lembrando que esses textos permitiram ver que cada um reuniu interferências mútuas entre: a cerâmica com a Literatura, a estampa com a pintura/arquitetura e, por último, a atmosfera fílmica animada com o Design da Comunicação. O pensamento criativo desses compositores habitou fronteiras não mais isolando elementos presentes em três movimentos que apresentaram aproximações primeiras, identificadas pelo acoplamento de um conjunto de relações materiais e de um regime de signos não correspondentes. Assim, se pode dizer da presença de um agenciamento capaz de produzir um mais alto grau de potência que traduzem novos jeitos de ver, perceber e criar (DELEUZE, 1997).

\subsection{Grade de referência (frameworks) - o semiaberto da forma de expressão}

Um framework é uma grade de referência para criação que une códigos comuns entre vários projetos de mesma natureza, provendo uma funcionalidade genérica advinda da regularidade e da semelhança dos meios de produção de determinadas coisas/produtos. As grades erguem uma importante e consistente estrutura (esqueleto) que prioriza os cuidados com as necessidades técnicas e produtivas para a execução e o funcionamentos de tais produtos. Dois escritos (STRECK; FRAGOSO, 2014; CARVALHO; ARAGÃO, 2012) mapearam conceitos e práticas que permitiram construir tais referências: uma para personagens de games e outra para infográficos estáticos. As primeiras autoras Streck e Fragoso (2014) alertam que a fórmula, a ser testada, está longe de ser completa, embora colabore para suprir lacunas importantes para a criação de personagens ${ }^{1}$ e avaliação dos já existentes. Além da grade que serve ao Design de Jogos, o texto destaca a importância do Design emocional para criação de personagens que venham a se relacionar com o jogador, para elas, um personagem literário interessante não é aquele com o qual o leitor estabelece uma relação contemplativa, mas sim, aquele que permite a ele se colocar

\footnotetext{
${ }^{1}$ Elementos para a composição de um personagem: a) fatores fisiológicos, sociológicos e psicológicos; b) Tipos básicos de personagens em games; c) Papeis sociais; d) Fatores de envolvimento com personagens; e) Aspectos psicológicos: socialização, dominância, personalidade; f) Tipos de emoções; g) Níveis emocionais; h) Estados afetivos e i) Relação emocional entre jogador e avatar (STRECK; FRAGOSO, 2014).
} 
em seu lugar - é preciso então que algo aconteça muito para além das formas fisiológicas e ilustrativas de um personagem é nesse aspecto que a variação acontece.

A outra grade de referência destina-se a criação de infográficos estáticos e foi proposta por Carvalho e Aragão (2012). Elas identificaram uma escassez conceitual específica sobre infografia (gênero editorial que utiliza recursos gráfico-visuais para apresentação da informação) e a partir daí, constituíram uma busca teórica sobre os preceitos da linguagem visual e os elementos que compõe um infográfico. Também realizaram entrevistas com designers produtores de infográficos já atuantes na prática profissional. A proposta de grade foi formulada a partir das análises sintática e semântica advindas da visão prática dos entrevistados e da visão teórica da revisão dos fundamentos do Design Gráfico. A grade ${ }^{2}$ proposta aponta as regularidades e semelhanças encontradas na produção dos infográficos, acabando por estabelecer uma maneira de produzi-los, uma ordem, que foi determinante para a construção da estrutura.

Os dois artigos dão a conhecer métodos, formas e maneiras de produzir e criar: personagens para games e infográficos editoriais. A necessidade de elaborar frameworks mostra o quanto boa parte da forma de expressão é semiaberta, pois está previamente estabelecida o que resulta também em justificar a formulação de tais grades de referência. Essa sistematização, em grade, consiste em elaborar uma estrutura (esqueleto) que diz de uma parte que compreende as necessidades formativas de confecção e de uso das coisas. Ela é, e deve ser, recorrente em outros tantos momentos da prática criativa do designer, o que resulta em reflexos importantes no resultado final do que é criado, já que reserva-se boa parte do tempo para entendê-las, adaptá-las enquanto se realiza o ajuste preciso que vai permitir identificar os espaços compositivos em meio a ela. Contudo, ao mesmo tempo em que o designer necessita formular e atender as sistematizações da produção e do uso final da coisa formulada, tem que encontrar o espaço compositivo, variando e resistindo as pré amarrações existentes no plano de expressão do produto/coisa criada. De tudo, o que a pesquisa maior quer problematizar são os aspectos que ajudam a determinar os espaços compositivos e até mesmo os movimentos de escape das grades onde justamente acredita-se que esteja o potencial criativo no Design.

\subsection{Entrelaçamentos e contaminações no processo criativo - escoamentos da grade}

Outros textos entram como uma explosão de sabores na boca permitindo sentir alguma coisa inexplicavelmente boa enquanto se produz muita saliva para avisar o pensamento da existência de algo inigualável. Esses sabores permitem dizer de uma linha de fuga que inventa outra direção permitindo escoar algo do sistema (da grade), a linha nasce de um pensamento que teima em não reformular o já existente. Marques et. al., (2012), primeiros produtores de sabores, oferecem um sentido reformulado sobre a oposição entre Design de moda e Artesanato apresentando outra possibilidade de leitura partindo da proposição de um entrelaçamentos entre eles. Os autores colocaram em cheque a visão dicotômica na relação Design e Artesanato, defendo, as

\footnotetext{
${ }^{2}$ A proposta metodológica abrangeu dez etapas subdivididas em três fases: concepção (compreende etapas de definição e apropriação do tema, assunto e público alvo), execução (elaboração de conteúdo e arquitetura da informação) e acabamento (união de texto e projeto gráfico, ajustes, revisões e análise crítica sobre o infográfico) (CARVALHO; ARAGÃO, 2012).
} 
contaminações, as diferenças e as aproximações entre os dois campos de atuação/produção, já que os processos criativos que buscam percursos experimentais fogem de lugares comuns. Nessa fuga, dizem eles, é que o designer faz um deslocamento para descobrir outros locais instalando-se em áreas que não são suas (originalmente), para isso é preciso habitar objetos já existentes, inventando trajetórias entre signos. A exemplo da obra de arte contemporânea que se coloca em um local de manobras, e não como produto acabado o Design também não deveria ser pensado como um "produto acabado", mas sim como um gerador de experiências. Nessa perspectiva, o Artesanato surge como potência para a experimentações e "troca entre aquilo que está embutido em sua materialidade e aquilo que pode ser depreendido delas por nossa experiência" (MARQUES et. al., 2012, p.35). O encontro com a materialidade do artesanato (bordados, tecelagens, colcha de retalhos, fuxicos, etc.) permite ativar o percurso experimental de particulares contaminações.

O outro escrito, também responsável pela explosão de sabores, ofereceu uma constatação singular e subjetiva sobre o designer que assim como o artista, o escritor ou o cineasta deixam suas marcas pessoais, contaminando a criação. Neste caso, a marca é bem mais visível e identificável já que abordam o gesto na produção de letreiros que resguardam em si as marcas de um punho humano (MIYASHIRO; GOUVEIA, 2012). O intuito foi deixar clara as aproximações entre Design gráfico, corpo e tipografia constatando a influência pessoal do gesto na forma de expressão dos letreiros (Design de tipos/fontes). Para os autores, o corpo se apresenta como elemento fundamental, pois envolve a relação com o ambiente, a cognição, os músculos e a memória revelada, sobretudo, através do gesto.

\begin{abstract}
A junção corpo e Design de tipos [...] é algo distante do universo da maioria das pessoas na área do Design Gráfico - o que causou certo estranhamento. Isso talvez porque o mundo do ensino e da prática do Design se preocupe com parâmetros e métodos de projeto, bem como com os resultados a serem alcançados, objetivos e práticos (MIYASHIRO; GOUVEIA, 2012, p.2424).
\end{abstract}

O estranhamento apontado pelos autores reforça a preocupação e a predominante atenção aos parâmetros (grades de referência) no momento da criação. Quase sempre os estudos do corpo são dedicados ao usuário e a adequação do projeto a suas necessidades funcionais e emocionais, se limitando a pensar o corpo para o qual se cria (o corpo do público alvo). Contudo, a oferta de um olhar singular e subjetivo sobre os gestos que é impresso pelo corpo de cada designer, alcança uma outra linha que quer reservar um espaço para aquilo que varia, por fuga, das pré amarrações do plano de expressão ditadas pelos Frameworks. Nessa direção, "o corpo - não é mero invólucro de uma mente que concebe o projeto, mas se assume como elemento que contamina totalmente a criação: é necessário, portanto, recontextualizá-lo" (MIYASHIRO; GOUVEIA, 2012, p. 2425). O exemplo mais claro está nas marcas da caligrafia japonesa manuscrita, ela carrega a força do punho em referência às capacidades cognitivas do corpo, local em que toda informação que chega entra em negociação com as que já estão e o corpo seria esse cruzamento, e não somente um lugar para abrigá-las.

Os dois escritos ofuscaram a mente pela força com que oferecem seus entrecruzamentos e contaminações da criação em Design de Moda e de Tipos que de formas distintas iluminam as rachaduras, as quebras na estrutura, saturando algo que 
faz fugir, escapar, escoar do conjunto. O produto artesanal e o gesto são matérias não formatadas que podem, no Design, entrar e sair passando por todos os estados, independente da interpretação, como a linha de fuga que tem seu início na grade mas corre em uma direção inesperada (DELEUZE; GUATTARI, 1997a).

\section{5 $\mathrm{Na}$ borderline da criação}

Outros textos coagularam e se mostraram menos saborosos se comparados aos devorados até então. Coagulam aspectos que se situam na borderline da criação, naquilo que diz algo anterior ou posterior ao produto criado, mas não diretamente ao seu processo constitutivo. Dessa concentração de sabores menos apetitosos buscou-se apenas citar como forma de respeito ao todo do alimento ofertado, mantendo assim a fidelidade aos critérios de seleção, dentre os quais situam-se:

- o intelectual autor e as necessidades de sistematizar um alinhamento da Área de Design à Área de Propriedade Industrial (BACKX,2014; NETO, 2012);

- a criação de diretrizes para a avaliação do desempenho ambiental da indústria gráfica (CASTILLO; LEÃO JÚNIOR, 2014);

- os registros fotográficos da criação de coleções em moda que traduzem parte do universo particular do criador (SOUZA, 2014);

- o trabalho imaterial nas redes de comunicação e cooperação produtiva (FERREIRA, 2014);

- os princípios e as aplicações do Design estratégico orientados para competitividade e organização nos investimentos e na gestão de negócios reinvenção da maneira de pensar do consumidor e o designer como intérprete do desejo de comprar (ALMEIDA, 2012); estratégias sinestésicas aplicadas ao espaço de interiores na criação de uma vitrine de experiências para o cliente (NUCCl et al. 2012) e gestão no desenvolvimento da marca - o Brand DNA Process (STODIECK ; GOMEZ, 2012);

- o Open Design - que é um novo modelo de produção, customização e distribuição de produtos fabricados através de sistemas digitais (ROSSI; NEVES, 2012).

Contudo, como dito logo no início, o texto de doutoramento quer se dedicar aos sentidos produzidos naquilo em que a academia foi capaz de criar, variar e experimentar, abordando um tipo de criação que ainda se permite alucinar sem as intemperes mercadológicas, já que elas se estabelecem no seio do ensino no ventre da academia. Não se quer com isso negar qualquer plano de negócio, mas sim firmar diferenças que digam de um não estilo de criação que só se faz por experimentação e variação. Talvez se possa melhor dizer das especificações que o Design atente: estratégicas, técnicas, criativas e produtivas, e que a academia melhor interaja com duas delas: as técnicas e as criativas já que as demais prescindem de sistemas complexos (materiais, máquinas industriais e de rotinas mercadológicas com clientes reais) difíceis de simular em sua totalidade.

\section{CONCLUSÃO}

Assim, cabe pensar que em alguma medida a devora produziu pistas sobre o que anda perpassando o processo de criação em Design nas academias do Brasil atual, 
nas formas destacadas que estabelecem o movimento que teima em reencarnar a vida no Design sintetizadas aqui pelos resultados mapeados. Dentre eles recorda-se os movimentos que dizem primeiro de uma maior aproximação das criações com a cultura (pau-Brasil) e com aspectos da limitação humana, marcando o afastamento da reprodução de tendências internacionais, contribuindo para desnaturalização da visão do Design como atividade de elite. Em sequência seguem as criações que agenciaram com arte e produziram modos alternativos de explorar entrecruzamentos em perspectivas singulares que habitaram fronteiras, acoplando elementos e estabelecendo o diálogo entre Arte e Design. Posteriormente encontra-se o entendimento da necessidade de elaborar, usar e criar os frameworks mostrando o quanto boa parte da forma de expressão do Design é semiaberta e previamente estabelecida, o que resulta em reflexos importantes no resultado final do que é criado, sendo que é na dedicação e no entendimento preciso das grades que será possível melhor explorar os espaços compositivos. Adiante temos as criações ou os pensamentos que escoam da grade, naqueles que tem variado e resistido as pré amarrações existentes no plano de expressão, os movimentos que advém do olhar sobre o gesto e a atividade artesanal que são ofertadas como formas de produzir novos pensamentos, saturando algo que faz escoar do conjunto. Por último encontrase os movimentos que ficam da borderline da criação situando aspectos de algo anterior ou posterior ao produto criado, mas não diretamente ao seu processo constitutivo. O mapa construído, a partir da revisão de literatura, serviu de base para melhor compreender alguns pontos incorporados as formas de criar das academias brasileiras. A trajetória agora quer renascer numa nova alvorada e continuar a descobrir que outras ramificações são possíveis a partir dos pontos mapeados.

\section{REFERÊNCIAS}

ALMEIDA, Alexandre M. A contribuição do Design Estratégico no processo de criação de novos produtos. p. 5247 - 5259. In: Anais do X Congresso Brasileiro de Pesquisa e Desenvolvimento em Design. São Luís: EDUFMA, 2012. Disponível em: <http://www.peddesign2012.ufma.br/anais> Acessado em: 15/out.2015.

BACKX, Hugo Borges. Criação intelectual em cursos de Design: autoria e titularidade. p. 1469-1480 . In: Anais do 110 Congresso Brasileiro de Pesquisa e Desenvolvimento em Design [Blucher Design Proceedings, v. 1, n. 4]. São Paulo: Blucher, 2014. Disponível em: $<$ http://pdf.blucher.com.br/designproceedings/11ped/00414.pdf > Acessado em: 21/jun.2015.

BAHIA, I. P; OLIVEIRA, G. H.; ALMEIDA. M. G. Ensino de Design no Brasil: considerações sobre a instalação e seus reflexos na atualidade. p. 6901-6904. In: Anais do X

Congresso Brasileiro de Pesquisa e Desenvolvimento em Design. São Luís: EDUFMA, 2012. Disponível em: <http://www.peddesign2012.ufma.br/anais> Acessado em: 04/jul.2015.

BALESTRIN, Flávia Regina. Bolsas criação e produção de estampas relacionando Design de superfície à cultura gaúcha. p. 1877-1888 . In: Anais do 110 Congresso Brasileiro de Pesquisa e Desenvolvimento em Design [Blucher Design Proceedings, v. 1, n. 4]. São Paulo: Blucher, 2014. Disponível em:< http://pdf.blucher.com.br/designproceedings/11ped/01320.pdf > Acessado em: 28/jun.2015. 
CARVALHO, Juliana G.; ARAGÃO, Isabella. Uma proposta de metodologia para criação de infográficos estáticos. p. 2152-2167. In: Anais do X Congresso Brasileiro de Pesquisa e Desenvolvimento em Design. São Luís: EDUFMA, 2012. Disponível em: <http://www.peddesign2012.ufma.br/anais> Acessado em: 09/out.2015.

CASTILLO, Leonardo Gómez; LEÃO JÚNIOR, Lucídio Cardoso. Criação de diretrizes para a avaliação do desempenho ambiental da indústria gráfica. p. 2006-2018. In: Anais do 110 Congresso Brasileiro de Pesquisa e Desenvolvimento em Design [Blucher Design Proceedings, v. 1, n. 4]. São Paulo: Blucher, 2014. Disponível em:< http://pdf.blucher.com.br/designproceedings/11ped/00310.pdf > Acessado em: 28/jun.2015

DELEUZE, G. GUATTARI, F. Mil Platôs, Capitalismo e Esquizofrenia. v.1. São Coordenação da tradução: Ana Lúcia de Oliveira Ed 34, São Paulo, 1995.

DELEUZE, G.; GUATARRI, F. Kafka: Por uma literatura menor. Rio de Janeiro: Imago Editora, 1977.

DELEUZE, G.; GUATTARI, F. O que é a filosofia? Rio de Janeiro: Ed. 34, 1992.

DELEUZE, Gilles; GUATTARI, Félix. Mil Platôs - capitalismo e esquizofrenia. Tradução de Suely Rolnik. São Paulo: Ed. 34, 1997a. v. 4. p. 393.

DELEUZE, Gilles; PARNET, Claire. L' Abécédaire de Gilles Deleuze. Entrevista com Gilles Deleuze. Editoração: Brasil, Ministério de Educação, "TV Escola", 2001. Paris: Editions Montparnasse, 1997. 1 videocassete, VHS, son., color.

FERREIRA, Mariana F. Trabalho imaterial e cooperação produtiva: considerações sobre a produção em Design a partir das redes de criação colaborativa. p. 3057-3069 .

In: Anais do 11 Congresso Brasileiro de Pesquisa e Desenvolvimento em Design. [Blucher Design Proceedings, v. 1, n. 4]. São Paulo: Blucher, 2014. Disponível em:< http://pdf.blucher.com.br/designproceedings/11ped/01113.pdf > Acessado em: 29/jun.2015.

LIMA, Edilene M. de; COSTA, Andrea F. de S. C.; CAMARGO, Andrea. A Representação de Signos Culturais Pernambucanos Através da Criação de Superfícies Têxteis. p. 2658 2672. In: Anais do X Congresso Brasileiro de Pesquisa e Desenvolvimento em Design. São Luís: EDUFMA, 2012. Disponível em: <http://www.peddesign2012.ufma.br/anais> Acessado em: 15/out.2015.

MAROSO, Elias. MINUZZI, Renilda de F. B. Vanguarda Futurista e Urbano Hoje: vetores de criação em Design têxtil. p. 3654 - 3666. In: Anais do X Congresso Brasileiro de Pesquisa e Desenvolvimento em Design. São Luís: EDUFMA, 2012. Disponível em: <http://www.peddesign2012.ufma.br/anais> Acessado em: 15/out.2015.

MARQUES FILHO, Adair; SILVA, Gisele C. F. da; CRILLANOVICK, Quéfren. Design e artesanato: entrelaçamentos conceituais sobre processos de criação na produção de vestuário/moda. In: Anais do X Congresso Brasileiro de Pesquisa e Desenvolvimento em Design. São Luís: EDUFMA, 2012. Disponível em: <http://www.peddesign2012.ufma.br/anais> Acessado em: 15/out.2015.

MARTINS, India M. A criação de atmosferas em Valsa com Bashir. p. 6593 - 6603. In: Anais do X Congresso Brasileiro de Pesquisa e Desenvolvimento em Design. São Luís: 
EDUFMA, 2012. Disponível em: <http://www.peddesign2012.ufma.br/anais> Acessado em: 15/out.2015.

MIYASHIRO, Rafael T.; GOUVEIA, Anna P. S. Gestos da Escrita: corpo e criação. p. 2423 2205. In: Anais do X Congresso Brasileiro de Pesquisa e Desenvolvimento em Design. São Luís: EDUFMA, 2012. Disponível em: <http://www.peddesign2012.ufma.br/anais> Acessado em: 15/out.2015.

NETO, Alberto. O protagonismo dos designers junto aos direitos de propriedade industrial brasileiros de marca e indicação geográfica: criação, registro e gestão. p. 2010 - 2022. In: Anais do X Congresso Brasileiro de Pesquisa e Desenvolvimento em Design. São Luís: EDUFMA, 2012. Disponível em: <http://www.peddesign2012.ufma.br/anais> Acessado em: 09/out.2015.

NUCCI, André L. C.; PINTO, Thais de C. L.; GOMEZ, Luiz S. R. Design de loja como experiência de marca: criação de valores para o novo consumidor. p. 4823 - 4831. In:

Anais do X Congresso Brasileiro de Pesquisa e Desenvolvimento em Design. São Luís: EDUFMA, 2012. Disponível em: <http://www.peddesign2012.ufma.br/anais> Acessado em: 15/out.2015.

PACHECO, Maiara Santana; MEDEIROS, Diego Piovesan; GONÇALVES, Marília Matos. Design inclusivo: criação de estampas em prol da inclusão social. p. 3470-3481. In: Anais do 11을 Congresso Brasileiro de Pesquisa e Desenvolvimento em Design. [Blucher Design Proceedings, v. 1, n. 4]. São Paulo: Blucher, 2014. Disponível em:< http://pdf.blucher.com.br/designproceedings/11ped/00092.pdf > Acessado em: 01/jul.2015.

ROSSI, Dorival C.; NEVES, Heloisa M.D. Open Design - Um novo modelo para criação, produção e distribuição de produtos. p. 1322 - 1341. In: Anais do X Congresso

Brasileiro de Pesquisa e Desenvolvimento em Design. São Luís: EDUFMA, 2012. Disponível em: <http://www.peddesign2012.ufma.br/anais> Acessado em: 09/out.2015.

ROSSO, Jonas C.; MEDEIROS, Diego P.; DAGOSTIM, Cristiane G. A Tradução Intersemiótica como ferramenta na criação de projetos de Design de Superfície: Mario Quintana, vida e obra por meio da superfície cerâmica. p. 2802 - 2814. In: Anais do X Congresso Brasileiro de Pesquisa e Desenvolvimento em Design. São Luís: EDUFMA, 2012. Disponível em: <http://www.peddesign2012.ufma.br/anais> Acessado em: 15/out.2015.

SOUZA, Yorrana P. Maia de. Cartografia de si: o processo de criação através dos territórios particulares e compartilhados no Instagram. p. 3118-3128. In: Anais do 110 Congresso Brasileiro de Pesquisa e Desenvolvimento em Design [Blucher Design Proceedings, v. 1, n. 4]. São Paulo: Blucher, 2014. Disponível em:< http://pdf.blucher.com.br/designproceedings/11ped/00647.pdf > Acessado em: 30/jun.2015

STODIECK, Walter F.; GOMEZ, Luiz S. R. A Utilização do Brand DNA Process na Criação de uma Marca de Empresa de Cervejas Diferenciadas. p. 2196-2204 - 2205. In: Anais do $X$ Congresso Brasileiro de Pesquisa e Desenvolvimento em Design. São Luís: EDUFMA, 2012. Disponível em: <http://www.peddesign2012.ufma.br/anais> Acessado em: 15/out.2015. 
STRECK, Melissa; FRAGOSO, Suely. Um framework para a criação e avaliação de personagens para games narrativos. p. 156-167. In: Anais do 11을 Congresso Brasileiro de Pesquisa e Desenvolvimento em Design [Blucher Design Proceedings, v. 1, n. 4]. São Paulo: Blucher, 2014. Disponível em:< http://pdf.blucher.com.br/designproceedings/11ped/ 00287.pdf > Acessado em: 21/jun.2015. 